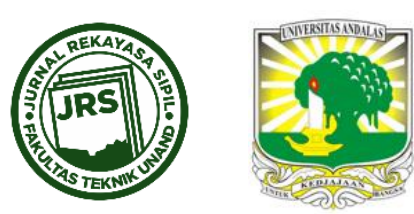

\title{
ANALISIS REVEAL DAN STATED PREFERENCE TERHADAP ATRIBUT TRAVEL TIME DAN TRAVEL COST PADA KOMPETISI MODA BUS DAN KERETA API: STUDI KASUS MALAYSIA
}

\author{
ANGELALIA ROZA ${ }^{1}$, ANDY MULYA RUSLI ${ }^{2}$, MOHAMED REHAN KARIM $^{3}$ \\ ${ }^{1}$ Institut Teknologi Padang \& Center for Transportation Research (CTR), Fakulti Kejuruteraan, Universiti Malaya, Kuala \\ Lumpur, Malaysia(ه angelaliaroza@gmail.com) \\ ${ }^{2}$ Kementrian Pekerjaan Umum dan Perumahan Rakyat, Direktorat Jendral Bina Marga (andimulyarusli@pu.go.id) \\ ${ }^{3}$ Center for Transportation Research (CTR), Fakulti Kejuruteraan, Universiti Malaya, Kuala Lumpur, Malaysia, \\ (rehan@um.edu.my)
}

Naskah diterima : 8 Januari 2017. Disetujui: 15 Februari 2017. Diterbitkan : 4 Maret 2017

\begin{abstract}
ABSTRAK
Penelitian ini bertujuan untuk menganalisa kompetisi moda angkutan umum darat antarkota di negara berkembang seperti Malaysia, terkait atribut travel time dan travel cost. Kajian ini menjadi penting karena kebijakan infrastuktur di negara berkembang seperti realisasi double tracking project ETS di Malaysia, berpotensi menimbulkan persaingan moda khususnya bus dan kereta api, terkait dua atribut tersebut. Pendekatan analisis dilakukan menggunakan reveal preference method yang dipertajam dengan stated preference method. Tingginya kompetisi moda angkutan umum darat antarkota ini memungkinkan terjadinya mode shift, yang dapat diprediksi melalui preferensi dan persepsi pengguna moda. Preferensi dan persepsi pengguna moda bus antarkota dideskripsikan dengan memunculkan analisis sensitivitas terhadap 12.000 data set. Melalui analisis sensitivitas, dijumpai adanya perbedaan persepsi pengguna bus terhadap kebijakan penyedia jasa dalam perubahan nilai utilitas kedua moda tersebut. Temuan studi ini menarik, dimana reduksi travel time dan penurunan travel cost yang sama pada kedua moda, belum tentu menghasilkan persentase mode shift yang sama. Pengguna bus terlihat kurang begitu responsif terhadap pengurangan travel time maupun travel cost moda saingannya. Sebaliknya, pengguna bus antarkota lebih khawatir terhadap bertambahnya travel cost dan travel time moda mereka (bus). Diharapkan kajian ini menjadi pertimbangan bagi pembuat kebijakan agar pembangunan infrastruktur lebih tepat sasaran menuju terciptanya balance mode share. Terutama bagi kebijakan yang menimbulkan persaingan angkutan umum darat antarkota di masa depan.
\end{abstract}

Kata kunci : Metoda stated preference, Reveal preference, Preferensi moda bus antarkota, Analisis sensitivitas.

\section{JARINGAN TRANSPORTASI DARAT DI MALAYSIA}

Dalam Rencana Malaysia kesembilan (9MP) jaringan transportasi dirancang untuk mendukung pergerakan kendaraan melalui jalan raya. Adanya kebijakan pemerintah untuk menghubungkan kota-kota besar dengan infrastruktur jalan yang lebih baik di negera ini, berdampak pada pembangunan tol berkualitas tinggi di sejumlah kota besar dan daerah 
perkotaan, mulai dari kuala lumpur ke arah utara, selatan dan ke arah timur (JPBD, 2005; JPBD 2010; Departement of Statistic, 2010).

Kebijakan infrastruktur seperti pembangunan expressway telah memfasilitasi pergerakan moda sehingga mejadi lebih cepat dan efisien. Hal ini memberi kontribusi munculnya kompetisi antara moda bus ekspers dan kereta api. Waktu tempuh bus menjadi lebih pendek dan frekuensi keberangkatan bus menjadi jauh lebih tinggi. Cakupan jaringan jalan yang lebih luas membuat bus ekspres menjadi lebih populer daripada kereta api di negara ini.

Sementara itu, keterbatasan cakupan jaringan KTMB di semenanjung malaysia telah lama menjadi kendala dalam per-kereta api-an di negara ini (Kumar, 2008). Jaringan KTMB masih belum terhubung dengan baik. Selain itu, keterbatasan sumber daya untuk lokomotif dan kru, rendahnya kecepatan kereta api ( $60 \mathrm{~km} / \mathrm{jam})$, sempitnya track (1 meter) dan rolling stock lama juga menjadi kendala tambahan (Abdul, et.al.,2008).

Namun, kereta api di Malaysia tetap digemari karena aksesibilitas menuju stasiun dinilai lebih baik. Moda kereta api juga memiliki keunggulan dibandingkan dengan moda angkutan jalan raya dari segi manfaat sosial ekonomi seperti minimnya jumlah kecelakaan dan polusi (Abdul, et.al.,2008). Dalam hal layanan tarif, kereta api KTMB menawarkan fasilitas tempat tidur (selain kursi) dan lebih nyaman dari pada bus (kursi standar), namun tentu saja dengan tarif yang lebih tinggi.

Negara Malaysia telah memiliki sekitar 2.200 kilometer rel kereta api (Abdul, et.al.,2008). Perkembangan terbaru infrastruktur kereta api saat ini adalah pembangunan rel ganda atau dikenal dengan double tracking project. Jalur Ipoh - Padang Besar (track Utara), jalur Seremban - Gemas, jalur Gemas - Johor Bahru dan jalur Pantai Timur adalah beberapa lokasi berlangsungnya proyek double track. Koridor KL-Ipoh-Rawang merupakan salah satu koridor proyek double track yang telah selesai.

\section{PERUMUSAN MASALAH}

Pada tahun 2010 KTMB memperkenalkan layanan kereta api listrik (ETS) yang berdampak terhadap persaingan moda angkutan darat di koridor KL-Ipoh. Kinerja moda kereta api di koridor ini telah meningkat dalam berbagai aspek, meskipun berpengaruh terhadap peningkatan travel cost. Terbukti setelah ETS dioperasikan, kompetisi antara kereta antarkota (sepanjang KL - Ipoh koridor) dan bus antarkota (sepanjang Expressway UtaraSelatan (NSE) mulai nyata. Bahkan di Jalur KL-Ipoh, moda angkutan udara sudah tidak beroperasi lagi. Pengguna kendaraan pribadi juga mulai berpindah menuju moda kereta api di Koridor KL-Ipoh ini.

Saat ini pengembangan jalur kereta api ganda dari Ipoh ke Padang Besar (yang melewati koridor Penang) masih dalam proses konstruksi. Situasi ini diperkirakan dapat mempengaruhi preferensi moda angkutan umum darat antarkota sepanjang koridor KLPenang di masa mendatang. Rendahnya kecepatan kereta api $(60 \mathrm{~km} / \mathrm{jam})$, sempitnya track (1 meter) dan rolling stock lama kini tidak lagi menjadi kendala. Dengan kebijakan tersebut, transportasi umum khususnya moda angkutan umum darat antarkota di koridor KL penang ini akan semakin kompetitif. Seiring dengan perbaikan infrastruktur per kereta apian di koridor ini, travel time kereta api akan berkurang, sehingga pengguna bus akan beralih menuju moda kereta api (mode shift). Maka preferensi terkait persepsi pengguna bus terhadap kedua moda yang kompetitif tersebut akan menjadi topik yang sangat menarik untuk dibahas. 


\section{TUJUAN PENELITIAN}

Tujuan Penelitian ini adalah untuk menganalisis preferensi pengguna bus antarkota terkait persepsi terhadap moda bus dan kereta api yang makin kompetitif dari segi atribut travel time (X1) dan travel cost (X2), menggunakan Stated Preference (SP) method dan Reveal Preference (RP) method.

\section{METODOLOGI}

\subsection{Pengambilan Data}

Data yang digunakan dalam penelitian ini adalah kombinasi dari data primer dan data sekunder. Data primer dikumpulkan melalui beberapa tahap preliminary survey dan field survey. Survei lapangan dilakukan selama tiga bulan di beberapa terminal bus antarkota dan stasiun kereta api di Kuala Lumpur dan Penang. Setiap hari, diperkirakan sekitar 1.218 penumpang bus antarkota dan 791 penumpang kereta api bergerak di koridor KL - Penang. Untuk keperluan data primer, survei lapangan ini akhirnya melibatkan 242 responden dalam analisis data SP dan RP. Jumlah ini memenuhi kriteria total responden yang diperlukan. Hensher (2003), dalam Ahern dan Tapley (2008), menyatakan bahwa jumlah ideal responden yang diperlukan per-desain adalah antara 30 dan 50 orang. Menurut Green (1991), dalam Field (2009), untuk menguji overal fit pada model regresi linier, ukuran sampel minimum yang dibutuhkan sama dengan $50+8 \mathrm{k}$ ( $\mathrm{k}=$ jumlah prediktor). Untuk keperluan pengolahan data SP, pengguna bus diperkenalkan pada dua skenario : skenario bus ekspres (25 data SP) dan skenario kereta api (25 data SP). Dengan demikian, dari 242 responden, diperoleh 6050 set data SP kereta api dan 6050 SP set data bus ekspres. Total 12,100 set data SP digunakan dalam pemodelan. Data sekunder diperoleh dari instansi pemerintah seperti Departemen Perhubungan (MOT), Suruhanjaya Pengangkutan Awam Darat (SPAD), Keretapi Tanah Melayu Berhad (KTMB), dan Malaysia Airport Holdings Berhad (MAHB) dan digunakan dalam analisis kompetisi moda.

\subsection{Disain Kuisioner}

Penyebaran kuisioner dengan paper based survey digunakan dalam pengmpumpulan data primer pada penelitian ini. Kuisioner tersebut dikembangkan berdasarkan model dissagregat karena kemampuannya dalam menghasilkan model yang lebih realistik. Pertanyaan yang diberikan dalam survey form terdiri dari tiga bagian dan dirancang dalam bentuk pertanyaan RP (Reveal Preference) dan pertanyaan SP (Stated Preference) seperti terlihat pada Tabel 4.1. Dalam pengumpulan data RP, pertanyaan dikembangkan untuk melihat bagaimana perilaku responden terkait dengan aspek sosial ekonomi dan karakteristik moda berdasarkan perjalanan aktual pengguna moda.

Dalam pengumpulan data SP, pertanyaan SP dirancang sedemikian rupa untuk menggambarkan respon pengguna jika penyelenggara moda memberlakukan kebijakan perubahan attribut pelayanan pada moda transportasi darat antar kota tersebut. Secara detail, kuisioner data SP dikelompokkan dalam 4 atribut yakni: travel time (X1), travel cost (X2), frequency (X3) dan access time (X4). Skenario terhadap perubahan nilai moda bus dan kereta api terkait dua atribut yang diamati pada penelitian ini disajikan dalam Tabel 1. 
Analisis Reveal Preference dan Stated Preference terhadap Atribut Travel Time dan Travel Cost pada Kompetisi Moda : Studi Kasus Malaysia

Tabel 1. Disain Kuisioner pada Tahap Pengumpulan Data

\begin{tabular}{|c|c|c|}
\hline Kuisioner & $\begin{array}{l}\text { Tipe } \\
\text { data }\end{array}$ & Isi Kuisioner \\
\hline $\begin{array}{l}\text { 1.Travel } \\
\text { characteristics parts } \\
\text { 2.Passenger } \\
\text { characteristic part } \\
\text { (Respondents socio- } \\
\text { economic) }\end{array}$ & $\begin{array}{l}\text { RP } \\
\text { data }\end{array}$ & $\begin{array}{l}\text { Respondents age, marital status, gender, monthly income, } \\
\text { monthly expenditure for transportation (transport budget), } \\
\text { expenditure for intercity transport (intercity budget), intercity } \\
\text { travel frequency, intercity bus fare (one way), intercity travel } \\
\text { trip purpose, feeder transport service mode (access and egress), } \\
\text { feeder transport travel time to terminal (access and egress), } \\
\text { feeder transport waiting time (access and egress), feeder } \\
\text { transport fare (access and egress), intercity bus mode choice } \\
\text { reason, passenger perception of distance effect, Intercity bus } \\
\text { competitor, intercity bus travel time (hour), intercity mode } \\
\text { waiting time, passenger occupation }\end{array}$ \\
\hline $\begin{array}{l}\text { 3.Intercity land public } \\
\text { transport service Part } \\
(2 \text { modes })\end{array}$ & $\begin{array}{l}\text { SP } \\
\text { data }\end{array}$ & $\begin{array}{l}\text { Scenarios of intercity land mode (bus and train) travel time } \\
\text { changes, scenarios of intercity land mode (bus and train) travel } \\
\text { cost changes, scenarios of intercity land mode (bus and train) } \\
\text { travel frequency changes, scenarios of intercity public transport } \\
\text { access time changes (to access bus and train station) }\end{array}$ \\
\hline
\end{tabular}

Tabel 2. Skenario Perubahan Pelayanan Moda Transportasi Darat Antarkota (2 dari 4

\begin{tabular}{|c|c|c|c|}
\hline Attribute & $\begin{array}{lr}\text { Intercity } & \text { Land } \\
\text { Public } & \text { Transport } \\
\text { Mode } & \end{array}$ & $\begin{array}{l}\text { Scenario of Service } \\
\text { Changes }\end{array}$ & $\begin{array}{l}\text { Variation in Service Changes } \\
\text { (Sub scenarios) }\end{array}$ \\
\hline \multirow{2}{*}{$\begin{array}{l}\text { Travel } \\
\text { time }\left(\mathrm{X}_{1}\right)\end{array}$} & Intercity bus & $\begin{array}{l}\text { If intercity bus travel } \\
\text { time were longer than } \\
\text { existing }\end{array}$ & $\begin{array}{l}\text { (8 sub scenarios) } 0 \%, 5 \% \text {, } \\
10 \%, 15 \%, 20 \%, 25 \%, 30 \% \text {, } \\
40 \%\end{array}$ \\
\hline & Intercity train & $\begin{array}{l}\text { If intercity train travel } \\
\text { time were shorter than } \\
\text { existing }\end{array}$ & $\begin{array}{l}\text { (8 sub scenarios) } 0 \%, 5 \%, \\
10 \%, 15 \%, 20 \%, 25 \%, 30 \% \text {, } \\
40 \%\end{array}$ \\
\hline \multirow{2}{*}{$\begin{array}{l}\text { Travel } \\
\text { cost } \\
\left(\mathrm{X}_{2}\right)\end{array}$} & Intercity bus & $\begin{array}{l}\text { If intercity bus fare were } \\
\text { increased than existing }\end{array}$ & $\begin{array}{l}\text { (8 sub scenarios) } 0 \%, 5 \%, \\
15 \%, 25 \%, 40 \%, 75 \%, 90 \% \text {, } \\
100 \%\end{array}$ \\
\hline & Intercity train & $\begin{array}{l}\text { If intercity train fare } \\
\text { were decreased than } \\
\text { existing }\end{array}$ & $\begin{array}{l}\text { (8 sub scenarios) } 0 \%, 5 \% \text {, } \\
15 \%, 25 \%, 40 \%, 75 \%, 90 \% \text {, } \\
95 \%\end{array}$ \\
\hline
\end{tabular}

\subsection{Persiapan Data}

Teknik mode choice diterapkan dalam pengumpulan data SP tersebut. Untuk menghitung probabilitas preferensi bus dan mengevaluasi persepsi pengguna bus, digunakan 4 pilihan keputusan penggunaan moda (Bertram, n. d.). Bentuk pertanyaan SP didesain seperti pada Tabel 3.

Pada tahap persiapan data menggunakan tools SPSS, dilakukan coding terhadap variabel socio-economy data terlebih dahulu. Data SP selanjutnya ditransformasi mengacu pada 4 variasi poin menggunakan transformasi linear logit biner model (persamaan 1).

$U_{B u s}-U_{\text {Train }}=\operatorname{Ln} \frac{P_{\text {Bus }}}{\left(1-P_{B u s}\right)}$

Hasil nilai transformasi terhadap 4 variasi poin keputusan penggunaan moda tersebut ditabelkan dalam Tabel 3 berikut.

Tabel 3. Transformasi Pertanyaan Pilihan Moda untuk data SP 


\begin{tabular}{llll}
\hline Mode Choice Statement & Point variations & Score & Transformation \\
\hline Surely Prefer Intercity Bus & 1 & 0.8 & 1.386294361 \\
\hline Maybe Prefer Intercity Bus & 2 & 0.6 & 0.405465108 \\
\hline Maybe Prefer Intercity train & 3 & 0.4 & -0.405465108 \\
\hline Surely Prefer Intercity train & 4 & 0.2 & -1.386294361 \\
\hline
\end{tabular}

\subsection{Teknik Analisa Data dan Pemodelan}

Fungsi utilitas dihitung dengan mengukur efek dari komponen atribut yang berhubungan dengan moda menggunakan regresi linear. Utilitas kedua moda digambarkan berupa dua model (model 1 dan 2) melalui persamaan 2 dan 3 berikut.

Model 1 (Bus Scenario):

$$
\begin{aligned}
& Y_{1}=U_{\text {Bus }}-U_{\text {Train }}=b_{0}+b_{1}\left(X_{1 \text { Bus }}-X_{1 \text { Train }}\right)+b_{2}\left(X_{2 \text { Bus }}-X_{2 \text { Train }}\right)+b_{3}\left(X_{3 \text { Bus }}-X_{3 \text { Train }}\right)+b_{4} \\
& \left(X_{4 \text { Bus }}-X_{4 \text { Train }}\right)
\end{aligned}
$$

Model 2 (Train Scenario):

$$
\begin{aligned}
& Y_{2}=U_{\text {Bus }}-U_{\text {Train }}=b_{0}+b_{1}\left(X_{1 \text { Bus }}-X_{1 \text { Train }}\right)+b_{2}\left(X_{2 \text { Bus }}-X_{2 \text { Train }}\right)+b_{3}\left(X_{3 \text { Bus }}-X_{3 \text { Train }}\right)+b_{4} \\
& \left(X_{4 \text { Bus }}-X_{4} \text { Train }\right)
\end{aligned}
$$

Tahap analisis lanjutan dari analisis fungsi utilitas tersebut adalah analisis sensitivitas. Persamaan (4) di bawah ini digunakan untuk menghitung probabilitas preferensi bus ( $\mathrm{P}$ Bus), mengacu pada Yannis et al. (2005).

$P_{\text {Bus }}=\frac{\exp \left(U_{\text {Bus }}-U_{\text {Train }}\right)}{1+\exp \left(U_{\text {Bus }}-U_{\text {Train }}\right)}$

Dimana P Bus = probabilitas pemilihan bus antarkota, $\mathrm{U}$ Bus = utilitas bus antarkota sesuai perubahan service value moda tersebut, dan U Train = utilitas kereta api sesuai perubahan service value moda tersebut.

\section{HASIL DAN PEMBAHASAN}

Gambaran awal tingginya kompetisi moda transportasi umum darat antarkota di koridor ini dapat dilihat melalui kondisi eksisting kedua moda terkait atribut travel time dan travel cost pada sub bagian 5.1. Melalui analisis RP pada sub bagian 5.2, sebetulnya dapat dikaji alasan tingginya preferensi bus, meskipun bus user diberikan pilihan alternatif moda lain di koridor tersebut. Setelah melakukan serangkaian preliminary survey dan mengidentifikasi enam faktor umum yang mempengaruhi preferensi moda dengan analisis RP, selanjutnya analisis tersebut dipertajam menggunakan Stated Preference method pada sub bagian 5.3. Ternyata dari enam faktor umum yang mempengaruhi preferensi moda, ada empat faktor yang perlu didiamati lebih lanjut dalam analisis SP yakni: atribut travel time (X1), travel cost (X2), frekuensi pelayanan (X3) dan waktu akses (X4). Melihat makin kompetitifnya persaingan moda transportasi umum darat antarkota di koridor ini, dua dari empat atribut yang terbukti signifikan mempengaruhi preferensi moda atribut menurut analisis RP dan SP, akan dibahas lebih dalam. Hal ini dapat diprediksi melalui preferensi dan persepsi pengguna moda, dengan memunculkan analisis sensitivitas pada sub bagian 5.4. Melalui analisis sensitivitas terkait atribut travel time (X1) dan travel cost (X2), dijumpai adanya perbedaan persepsi pengguna bus terhadap kebijakan penyedia jasa kedua moda tersebut yang dipaparkan pada sub bagian 5.5 . 


\subsection{Kompetisi Eksisting Moda Terkait Atribut Travel Time Dan Travel Cost}

Sengitnya kompetisi kedua moda angkutan darat antarkota di koridor KL-Penang ditunjukkan dalam Tabel 5.1 berikut. Bus ekspres sebagai moda transportasi umum darat dinilai sangat menguntungkan dari segi waktu perjalanan. Waktu tempuh kereta api jauh lebih lama dari pada bus ekpres karena kecepatan nya yang jauh lebih rendah $(60 \mathrm{~km} / \mathrm{jam}$ sepanjang jarak $388 \mathrm{~km}$ ) dibandingkan dengan bus ekspres (98 km/jam sepanjang jarak 369 $\mathrm{km}$ ). Biasanya hanya ada dua kali pemberhentian selama bus bergerak, sedangkan pada moda kereta api terdapat 12-19 kali pemberhentian sepanjang rute dari KL ke Penang. Bila ditambahkan dengan waktu akses menuju terminal, total waktu perjalanan kereta api konvensional akan menjadi jauh lebih lama (8.67 jam) bila dibandingkan dengan bus ekspress (6.63 jam).

Untuk menjawab tantangan kompetisi moda terkait atribut travel time ini, penyelenggara moda kereta api telah melakukan banyak perbaikan. Proses konstruksi rel ganda (double track) kereta api listrik ETS yang telah dilakukan. Nantinya, diperkirakan kereta api listrik ETS berkecepatan tinggi akan beroperasi disepanjang koridor KL - Penang ini. Dengan kecepatan max $160 \mathrm{~km} / \mathrm{jam}$ ditambah waktu akses menuju stasiun yang diperkirakan 30 menit, maka total waktu tempuh ETS dapat dipersingkat menjadi 2.90 jam. Artinya, waktu perjalanan kereta api listrik ETS akan jauh lebih singkat dari pada bus ekspres (6.63 jam).

Tabel 4. Kompetisi Moda Angkutan Darat: Bus Antar Kota Vs Kereta Api

\begin{tabular}{ll} 
Indicator & Value (existing condition) \\
\hline $\mathrm{X}_{2 \text { Bus }}=$ Intercity bus fare $\left(2^{\text {nd }}\right.$ Class bus service $)$ & $\mathrm{RM} \mathrm{33}$ \\
\hline $\mathrm{X}_{2 \text { Train }}$ Intercity train fare $\left(2^{\text {nd }}\right.$ Class train service $)$ & $\mathrm{RM} \mathrm{40}$ \\
\hline $\mathrm{X}_{2 \text { Bus }}-\mathrm{X}_{2 \text { Train }}=$ Intercity mode fare difference & $(-) \mathrm{RM} 7.0$ \\
\hline $\mathrm{X}_{1 \text { Bus }}=$ Intercity bus travel time & 5.5 hours \\
\hline $\mathrm{X}_{1 \text { Train }}=$ Intercity train travel time & 7.5 hours \\
\hline $\mathrm{X}_{1 \text { Bus }}-\mathrm{X}_{1 \text { Train }}=$ Intercity mode travel time difference & -120 minutes \\
\hline
\end{tabular}

Selain dari segi travel time, kompetisi moda angkutan darat antarkota dari segi travel cost perjalanan juga dapat dilihat pada Tabel 5.1. Di koridor ini, tarif bus antar kota bergantung pada jenis dan kelas moda yang tersedia. Pada dasarnya tarif bus ekspres (kelas 2; RM 33.00) lebih murah dibandingkan kereta antarkota (RM 40.00). Meskipun demikian, sebenarnya ada tarif tambahan untuk moda akses menuju terminal yang harus dipertimbangkan pengguna moda.

\subsection{Analisa data RP (Reveal Preference)}

Analisa data RP telah dilakukan terhadap 242 responden sebagai pengguna moda angkutan darat antar kota, berkaitan dengan kondisi sosial ekonomi mereka, termasuk analisa karakteristik moda berdasarkan perjalanan aktual pengguna moda pada koridor tersebut. Namun pembahasan penelitian kali ini lebih difokuskan pada faktor yang mempengaruhi pemilihan moda angkutan darat antarkota tersebut.

Pada penelitian sejenis, Hensher dan Rose (2007) menekankan bahwa semakin meningkatnya usia dan pendapatan individu, setiap individu akan cenderung mencari kualitas pelayanan yang lebih memuaskan. Demikian pula halnya dengan pemilihan layanan moda transportasi umum khusunya angkutan darat antar kota. Yang et al. (2009) menyatakan bahwa dalam memutuskan untuk menggunakan transportasi umum, pengguna biasanya mempertimbangkan waktu akses moda, waktu tunggu moda, jumlah 
transfer/transit, tarif transit, kepemilikan pass transit, dan fleksibilitas jadwal. Jika tidak ada layanan transportasi umum yang tersedia, mobil pribadi akan menjadi alternatif. Ini adalah bukti implisit bahwa ketersediaan moda transportasi merupakan faktor penting. Namun, penggunaan mobil pribadi untuk perjalanan antarkota yang cenderung lama, sepertinya tidak begitu disukai karena pengguna harus mempertimbangkan biaya bahan bakar, tol, kepemilikan pass transit, fleksibilitas jadwal dan jumlah penumpang.

Pada studi kasus ini, ditemukan enam faktor umum yang mempengaruhi preferensi moda pada perjalanan antarkota. Alasan utama bagi reponden dalam memilih moda transportasi antarkota adalah travel cost $(30,2 \%)$ dan waktu perjalanan $(25,2 \%)$. Sedangkan responden lainnya memilih mode antarkota karena alasan frekuensi pelayanan moda $(13,2 \%)$ dan aksesibilitas terminal $(21,5 \%)$. Keamanan tampaknya menjadi pertimbangan hanya bagi $1,7 \%$ responden. Sisanya, sebanyak $8,3 \%$ responden pada survei ini sependapat bahwa ketersediaan moda tranportasi pada koridor tertentu sangat mendasari pemilihan moda.

Terkait alasan ketersediaan moda, bus ekspres memang menjadi moda dominan yang banyak diminati. Hal ini disebabkan sebagian responden tidak memiliki alternatif moda dan di koridor tertentu memang tidak tersedia transportasi umum antarkota selain bus ekspres. Meskipun bus dikenal sebagai moda favorit, kereta api merupakan pesaing utama bus ekspres untuk perjalanan antarkota. Nyatanya, sebagian besar pengguna bus lebih memilih kereta api $(47,9 \%)$ sebagai alternatif moda bus ekspres, bukan mobil pribadi $(28,9 \%)$ atau moda lainnya $(23,2 \%)$.

\subsection{Analisa data SP (Stated Preference)}

Dissagregat analisis terhadap utilitas bus membuktikan keempat variabel yang diamati yakni; Travel Time Difference (min), Fare difference (RM), Frequency Difference (Departure/ day), dan Access Time Difference (min) terbukti secara signifikan mempengaruhi $(\mathrm{p}$-value $<0.05)$ preferensi moda.

Tabel 5. Utiitas Bus Akibat Perubahan Nilai Atribut

Utilitas Bus Akibat Perubahan Nilai Atribut Bus

Utilitas Bus Akibat Perubahan Nilai Atribut

Antarkota*

\begin{tabular}{|c|c|c|c|c|c|}
\hline \multirow[t]{2}{*}{$\begin{array}{l}\text { Mo } \\
\text { del }\end{array}$} & $\begin{array}{l}\text { Unsta } \\
\text { ndardi } \\
\text { zed } \\
\text { Coeffi } \\
\text { cients }\end{array}$ & $\begin{array}{l}\text { Standar } \\
\text { dized } \\
\text { Coeffs }\end{array}$ & $\mathrm{t}$ & \multirow[t]{2}{*}{ Sig. } & \\
\hline & B & $\begin{array}{l}\text { Std. } \\
\text { Error }\end{array}$ & Beta & & \\
\hline $\begin{array}{l}\text { cons } \\
\text { tant }\end{array}$ & -3.4 & .058 & & -59.930 & $\begin{array}{l}- \\
3.456 \\
\end{array}$ \\
\hline $\mathrm{X}_{1}$ & -.018 & .000 & $\begin{array}{l}- \\
.702\end{array}$ & -73.241 & -.018 \\
\hline $\mathrm{X}_{2}$ & -.059 & .001 & -627 & -65.992 & -.059 \\
\hline $\mathrm{X}_{3}$ & .107 & .003 & .383 & 41.924 & .107 \\
\hline $\mathrm{X}_{4}$ & -.035 & .001 & $-\overline{-} .580$ & -61.764 & -.035 \\
\hline
\end{tabular}

\subsection{Hasil Analisis Sensitivitas}


Probalitas pemilihan bus antarkota dapat dipengaruhi oleh perubahan nilai atribut bus antarkota terhadap kereta api. Penilaian utilitas bus antarkota terhadap kereta api tersebut mengacu pada keempat faktor yang telah teruji signifikan pada analisis stated preference sebelumnya. Analisis utilitas bus ekspress dilakukan terhadap skenario bus dan skenario kereta api. Dalam skenario bus, nilai atribut pelayanan bus ekspes (X1 Bus, X2 Bus, X3 Bus, and X4 Bus) disetting berubah saaat nilai atribut kereta api dianggap konstan. Akibatnya utilitas bus (U bus) akan berubah saat utilitas kereta api (U train) bernilai konstan. Didapati bahwa selisih nilai atribut waktu perjalanan (X1), tarif (X2), frekuensi keberangkatan (X3) dan waktu akses (X4) terbukti signifikan mempengaruhi utilitas preferensi bus.

Dari keempat atribut yang terbukti signifikan mempengaruhi preferensi bus sebagai moda angkutan darat antarkota, ada dua atribut yang sangat menarik untuk didiskusikan, yakni atribut waktu tempuh dan tarif(Roza, et.al.,2013). Analisis sensitifitas telah dilakukan untuk mengamati bagaimana sebetulnya persepsi pengguna bus ekspres terhadap perubahan nilai atribut tersebut. Dari analisis data SP pada kedua hasil model regresi tersebut, koefisien selisih nilai atribut waktu perjalanan (X1), tarif (X2) bernilai negatif. Ini berarti bahwa meningkatnya nilai waktu tempuh bus, tarif bus dan waktu akses moda ke terminal bus antarkota akan menurunkan preferensi bus ekspres.

\subsection{Persepsi Pengguna Bus Terhadap Atribut Travel Time dan Travel Cost}

Hasil analisis sensitivitas preferensi bus terhadap selisih nilai atribut waktu disajikan pada Gambar 1 di bawah ini. Sumbu x merupakan selisih waktu tempuh antara bus ekspes dengan kereta api dalam satuan menit. Ada dua garis yang terlihat pada Gambar 1 untuk mensimulasikan perubahan probabilitas bus berdasarkan dua model menggunakan persamaan 2 dan 3. Garis skenario bus (model 1) mewakili penambahan travel time bus ekspres sedangkan garis skenario kereta api (model 2) mewakili penurunan travel time kereta api. Dapat diamati bahwa penambahan waktu tempuh bus (120 menit) akan menyebabkan perpindahan $48,8 \%$ pengguna moda bus ekspres menuju moda kereta api. Dan pengurangan waktu tempuh kereta api (120 menit) akan menyebabkan perpindahan $40,7 \%$ pengguna moda bus ekspres menuju moda kereta api.

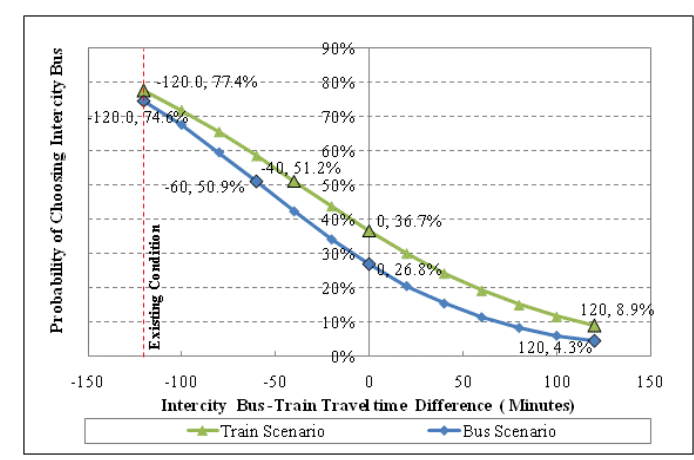

Gambar 1. Sensitivitas Preferensi Bus terhadap Perubahan Atribut Waktu Tempuh.

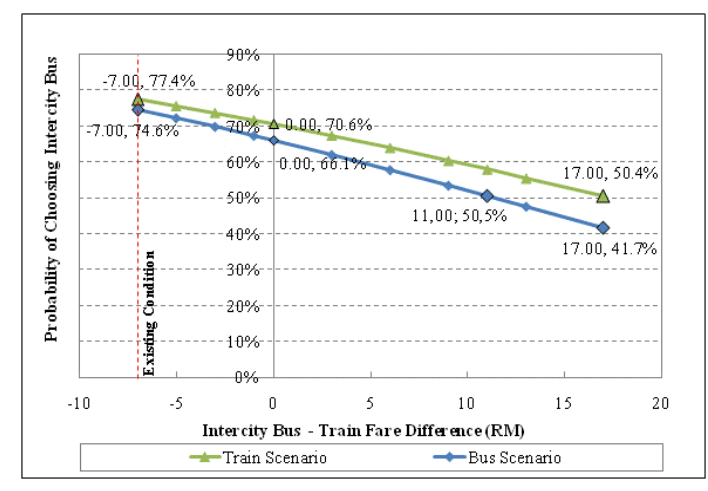

Gambar 2. Sensitivitas preferensi bus terhadap perubahan atribut tarif.

Dari hasil analisis sensitivitas ini terlihat bahwa pengguna bus kurang responsif terhadap pengurangan waktu tempuh kereta api. Padahal penyedia jasa kereta api telah melakukan sejumlah upaya peningkatan pelayanan dengan investasi yang sangat besar untuk mempersingkat total waktu perjalanan kereta api seperti dengan mengurangi waktu perjalanan, waktu tunggu ataupun waktu henti. 
Dari hasil pemodelan kedua garis skenario tersebut, justru terlihat bahwa efek perubahan probabilitas preferensi bus akan menjadi jauh lebih kuat saat bertambahnya waktu tempuh bus. Diduga, saat musim perayaan tertentu yang menimbulkan kemacetan jalan raya, responden cenderung lebih termotivasi untuk beralih pada moda kereta api. Fenomena ini mungkin akan berimbas pada tinggi nya permintaan untuk pengembangan infrastruktur jalan raya, karena penyediaan angkutan umum dengan saham modal yang lebih rendah berbanding infrastruktur kereta api ini dapat memberikan kontribusi untuk solusi kemacetan lalu lintas. Hal ini tentu saja menjadi tantangan besar bagi pemerintah khususnya SPAD (Suruhanjaya Pengangkutan Awam Darat) dan industri bus di masa depan.

Persepsi pengguna bus dalam hal perubahan atribut waktu tempuh untuk moda bus dan kereta api terlihat sedikit berbeda. Mungkin ada pertimbangan lain yang terkait dengan waktu tempuh misalnya faktor kenyamanan. Dalam sesi wawancara, banyak pengguna bus yang mengaitkan waktu tempuh dengan kenyamanan, dimana penggunaan moda bus dianggap lebih nyaman karena waktu tempuh yang relatif singkat. Diperlukan penelitian lebih lanjut terhadap dugaan ini.

Sementara itu, hasil analisis sensitivitas preferensi bus terhadap selisih nilai atribut tarif disajikan pada Gambar 2 di atas. Sumbu x merupakan selisih tarif antara bus ekspes dengan kereta api dalam satuan Ringgit Malaysia (RM). Dalam simulasi, Garis skenario bus mewakili peningkatan tarif bus ekspres sedangkan garis skenario kereta api mewakili penurunan tarif kereta api.

Dalam Gambar 2, diamati bahwa kenaikan tarif eksisting moda bus senilai RM7 dapat memicu terjadinya perpindahan moda dari bus ke kereta api. Dijumpai, probabilitas mode shift yang lebih tinggi terjadi akibat kenaikan tarif bus (8,5\%), berbanding akibat penurunan tarif kereta api $(6,8 \%)$ dalam harga yang sama. Menariknya, pengguna bus ternyata tidak dengan mudah merespon penurunan tarif moda kerta api dengan segera beralih menggunakan moda tersebut. Tersirat bahwa pengguna bus cenderung lebih khawatir mengenai kenaikan tarif moda bus saat ini.

Dalam perspektif ekonomi, seharusnya nilai uang yang dikeluarkan responden terhadap kedua moda tidak memiliki perbedaan yang berarti. Namun berdasarkan hasil analisa sensitivitas, nyatanya pengguna bus memiliki persepsi yang berbeda tentang nilai perubahan atribut tarif bus ekspres dan kereta api tersebut. Ini merupakan temuan yang menarik, dimana penetapan tarif yang sama untuk moda bus ekspres dan moda kereta api, belum tentu memberikan daya tarik moda yang sama. Mungkin ada alasan lain yang perlu dianalisa lebih lanjut terkait perspektif pengguna bus, yang belum terkaji dalam model ini. Bisa saja hal tersebut berkaitan dengan biaya tambahan yang perlu diperlukan pengguna moda berkaitan dengan aksesibilitas menuju terminal moda antarkota.

\section{KESIMPULAN DAN SARAN}

Kebijakan pemerintah dalam mengarahkan pembangunan infrastuktur seperti realisasi double tracking project dan kereta api listrik ETS, cenderung membawa dampak signifikan terhadap persaingan moda khususnya angkutan darat di negara ini. Realisasi proyek rel ganda (double track) di koridor yang bersinggungan dengan KL- Penang dalam waktu dekat, tentu akan memicu terjadinya mode shift dan kemungkinan penurunan preferensi bus. Ini merupakan akibat ketertarikan pengguna bus terhadap perubahan atribut tertentu seperti travel time dan travel cost. 
Lebih lanjut, analisa persepsi pengguna bus berkaitan dengan atribut waktu tempuh dan tarif, memberikan temuan yang menarik. Efek perubahan probabilitas preferensi bus diamati jauh lebih kuat dengan bertambahnya waktu tempuh bus. Fenomena ini mungkin akan berimbas pada tinggi nya permintaan untuk pengembangan infrastruktur jalan raya. Maka jalur khusus untuk bus ekspres dapat direkomendasikan dalam menghadapi tantangan ini. Namun sebagai pertimbangan eksekusi kebijakan ini, terlebih dahulu perlu dilakukan pengamatan lebih lanjut terhadap pengguna kendaraan pribadi.

Sehubungan dengan perubahan nilai atribut tarif, dijumpai bahwa probabilitas mode shift yang lebih tinggi terjadi akibat kenaikan tarif bus, berbanding akibat penurunan tarif kereta api dalam harga yang sama. Hal ini menimbulkan kekhawatiran terhadap isu kelanjutan operasi bus antarkota yang selama ini dijalankan oleh sektor swasta. Menghadapi tantangan ini, pemerintah melalui Suruhanjaya Pengangkutan Awam Darat (SPAD) dinilai penting untuk segera merumuskan kebijakan industri angkutan umum darat antarkota dinegara ini. Bila perlu, pemerintah dapat mempertimbangkan kebijakan perlindungan kepada perusahaan bus misalnya dengan memberlakukan kebijakan subsidi.

\section{DAFTAR KEPUSTAKAAN}

Abdul, M., Ibrahim, Y., Hun, G. M. Case5, Keretapi Tanah Melayu Bhd. Asian Journal of Case Research, 1(2), 163-182. 2008.

Department of Statistics. Taburan penduduk dan ciri-ciri asas demograf. 2010.

Field, A. Discovering statistic using SPSS. London: Sage. 2009

Hensher, D. A. dan Rose, J. M. Development of commuter and non-commuter mode choice models for the assessment of new public transport infrastructure projects: A case study. Transportation Research Part A: Policy and Practice, 41, 428-443. 2007.

Jabatan Perancangan Bandar dan Desa Semenanjung Malaysia (JPBD). National Physical Plan 2. 2010.

Jabatan Perancangan Bandar dan Desa Semenanjung Malaysia (JPBD). National Physical Plan. Kuala Lumpur, Malaysia. 2005.

Roza, A., Koting, S., \& Karim, M. R. Intercity land public transport challenges in developing country: A case study in Peninsular Malaysia. Paper presented at the Proceeding Journal of the Eastern Asia Society for Transportation Studies (EASTS), Taipe, Taiwan. 2013

Yang, L., Choudhury, C. F., Ben-Akiva, M. Stated preference survey for new smart transport modes and services: Design, pilot study and new revision. Working Paper Series: Instituto Superior Tecnico, Universidade Tecnica de Lisbon, Portugal. 2009.

Yannis, G., Kanellopoulou, A., Aggeloussi, K., Tsamboulas, D. Modelling driver choice towards accident risk reduction. Safety science, 43, 173-186. 2005. 